\title{
UM FEIXE LUMINOSO: UMA LEITURA DA COLEÇÃO DE LITERATURA ELETRÓNICA PORTUGUESA
}

\author{
Álvaro Seiça* \\ 0.1. Este livro não é o resultado de nenhuma \\ prática poética no país hoje violado do verbo \\ humano. É tão só o relato provisório de uma \\ pesquisa no reino aventuroso da palavra \\ mecânica. \\ Pedro Barbosa, A Literatura Cibernética 1: \\ Autopoemas Gerados por Computador (1977: 7)
}

RESUMO: A Coleção de Literatura Eletrónica Portuguesa (CLEP), na base de dados ELMCIP, pretende abordar e recolher as obras criativas e teóricas mais relevantes produzidas por autores portugueses no campo da literatura eletrónica, durante os últimos quarenta e cinco anos. A coleção agrega também autores, eventos, organizações, editoras, periódicos, publicações, conferências, performances, instalações e exposições que estejam relacionadas com o contexto português.

O presente ensaio analisa criticamente a CLEP, em torno de elementos literários, políticos, históricos, estéticos e tecnológicos, através de um fio condutor representado por um "feixe luminoso", que pretende dar conta da transição e continuidade temática e medial, mas também da transgressão e ruptura, produzidas pela vanguarda do movimento de Poesia Experimental dos anos 1960 até aos ambientes computacionais de criação literária do século 21 . Ao longo desta leitura, analisa-se igualmente várias obras de Pedro Barbosa, E. M. de Melo e Castro, Silvestre Pestana, Manuel Portela e Rui Torres.

PALAVRAS-CHAVE: Coleção de Literatura Eletrónica Portuguesa. Literatura Portuguesa Experimental. PO.EX. Videopoesia. Poesia Digital.

\section{A Base de Dados ELMCIP Electronic Literature Knowledge Base}

A Electronic Literature as a Model of Creativity and Innovation in Practice (ELMCIP) é um projeto de investigação (2010-2013) que juntou vários parceiros universitários europeus, da Noruega, Suécia, Finlândia, Holanda, Escócia, Inglaterra, Eslovénia, e uma estrutura não-académica, a New Media Scotland. O projeto é coordenado por Scott Rettberg, da Universidade de Bergen, na Noruega,

PhD Fellow, Universidade de Bergen, Noruega. http://alvaroseica.net / Imeio: alvaro.seica@lle.uib.no

Esta obra está licenciada com uma Licença Creative Commons.

Texto Digital, Florianópolis, Santa Catarina, Brasil, v. 11, n. 1, p. 387-419, jan./jun. 2015. ISSNe: 1807-9288. 
e teve como principal resultado - para além de conferências, exposições, oficinas, seminários, antologias (e. g. literatura eletrónica europeia), vídeos e diversas publicações já realizadas - o desenvolvimento da ELMCIP Electronic Literature Knowledge Base (http://elmcip.net).

Iniciada em 2010 com o intuito de se tornar uma base de dados online aberta e colaborativa, e construída para esse efeito na plataforma Drupal, a ELMCIP Knowledge Base constituiu-se como o projeto de referência da unidade de investigação Bergen Electronic Literature Research Group. A base de dados, que está disponível na Internet e conta já com mais de 10.000 entradas (desde 5 de Fevereiro de 2015), pretende ser um modelo no domínio das humanidades digitais: 1) proporciona a introdução e edição de conteúdo por qualquer utilizador, o livre acesso e a partilha de conhecimento no campo da literatura eletrónica; 2) facilita a preservação e arquivo de obras digitais, ao mapear a criação e teoria com diferentes géneros de entradas de conteúdo: autores/pessoas, obras criativas, obras teóricas, eventos, organizações, editoras e revistas, bases de dados e arquivos, recursos de ensino e coleções de investigação; 3) aprofunda a atestação e contextualização das descrições publicadas com ficheiros multimédia (documentos, imagens, vídeos), anexados direta ou indiretamente no seu website - para uma informação detalhada, cf. o relatório do projeto, de Eric Dean Rasmussen (antigo editor da base de dados) e Scott Rettberg (2013), ou a monografia mais recente que aborda o assunto (2014).

A ELMCIP KB inspirou-se no "sistema em curso de documentos interconectados" ${ }^{\text {, }}$ proposto por Theodor Holm Nelson (1981, p. 2/9), e na relação de conceitos de agência e atores exposta na teoria-ator-rede (ANT) de Bruno Latour $(1987,2005)$ e Michel Callon. Possuindo um carácter wiki, uma das suas principais contribuições práticas é a forte referência cruzada que se gera nas diferentes entradas de conteúdo, completando-se de modo automático quando se adicionam novas entradas que referenciam outras já existentes. Este aspecto possibilita hiperligações dentro da própria estrutura - o que proporciona um grau

\footnotetext{
${ }^{1}$ Tradução livre do original: "ongoing system of interconnecting documents".

Texto Digital, Florianópolis, Santa Catarina, Brasil, v. 11, n. 1, p. 387-419, jan./jun. 2015. ISSNe: 1807-9288.
} 
de compreensão do campo da literatura eletrónica mais abrangente e imediato, e um grau de documentação da recepção crítica das obras mais produtivo, a longo prazo, quer para os criadores, quer para os estudiosos ou académicos interessados nesta área.

Outra característica que me parece importante realçar é pedagógica: por um lado, a base de dados, possuindo entradas para disciplinas já leccionadas, inclui a descrição, currículo e referências, o que permite o seu uso como ferramenta de apoio nas aulas, em todo o mundo; por outro lado, através da hipótese de qualquer utilizador criar coleções de investigação, potencia a pesquisa sobre determinado tópico livre, o que aumenta e concentra o conhecimento sobre um tema já presente ou não na base de dados.

\section{Desenvolvendo uma Coleção de Investigação na ELMCIP Knowledge Base}

\subsection{Objetivos da Investigação}

Quando iniciei a coleção de investigação "Portuguese Electronic Literature Collection" (PELC) ${ }^{2}$, em agosto de 2013, tive três objetivos principais:

a) expandir o meu conhecimento sobre o panorama português nesta área, aprofundando não só o estudo das obras criativas e teóricas, mas também o pioneiro trabalho já desenvolvido pelos dois projetos de investigação do PO.EX, o Arquivo Digital da Literatura Experimental Portuguesa, coordenado por Rui Torres na Universidade Fernando Pessoa, no Porto;

b) construir e hospedar no mesmo URL um corpo agregador de várias entradas já existentes, embora dispersas, na ELMCIP KB, alargando-as e inserindo novas referências, tendo em vista melhorá-lo, para:

c) valorizar, disseminar e avaliar a produção portuguesa no âmbito da literatura eletrónica, dos estudos literários, distribuindo-a pelas comunidades científicas e criativas que se interessam por este domínio e, de um modo mais

\footnotetext{
${ }^{2}$ Vertendo para português: Coleção de Literatura Eletrónica Portuguesa (CLEP). 
abrangente, visto que se encontra em livre acesso na Internet, disponibilizá-la para qualquer público.

\subsection{Contexto de Investigação}

É necessário, contudo, contextualizar o processo de investigação, visto que outras coleções orientadas pelo conceito de nacionalidade, região cultural ou língua haviam já sido criadas. Estas coleções permitiram uma maior atividade na base de dados, visto que os seus editores criaram milhares de novas entradas abrangendo países e línguas até aí pouco tratadas neste campo de investigação internacional. A publicação destas coleções reuniu entradas dispersas e levou à concentração de grupos com menor recepção crítica: em 2012, a Coleção de Referências Polacas, editada por Patricia Tomaszek, a Coleção de Literatura Eletrónica Brasileira, editada por Luciana Gattass, e a Coleção de Literatura Eletrónica Nórdica, editada por Melissa Lucas; e, em 2013, a Coleção de Literatura Eletrónica Russa, editada por Natalia Fedorova. No momento em que iniciei a Coleção de Literatura Eletrónica Portuguesa, Maya Zalbidea começou igualmente a Coleção de Literatura Eletrónica de Língua Espanhola, desenvolvida sobretudo no Verão de 2014. No Outono de 2014, Jonathan Baillehache começou a editar a Coleção de Literatura Eletrónica Francesa.

Neste sentido, há alguns pontos que importa referir:

a) a CLEP não procura o conceito de nacionalidade per se, na perspectiva catalisada pelo Romantismo, pelo Estado-nação, e posta em prática durante os séculos 19 e 20 na divisão dos curricula das literaturas nacionais dos departamentos universitários de filologia e literaturas modernas;

b) porém, o desenvolvimento de uma coleção disponível na Internet, orientada por um conceito comum de língua e cultura, e por um cenário artístico, cultural e político, concentra o conhecimento, beneficia o acesso, a análise de outras pessoas e a compreensão de fatores idiossincráticos;

c) tal princípio, apesar de permitir uma visão comparatista, paradoxalmente descarta e promove fatores imediatos de relevância populacional, social, 
económica e geopolítica, mas não a sua tradução literária e política mais lata na temática e contexto de produção dos seus autores, concentrando-se no fenómeno literário numa perspectiva mais globalizante, pela crescente comunicação em rede entre países, regiões, línguas e autores, advogando a literatura eletrónica ${ }^{3}$ como literatura do mundo, ou weltliteratur (Goethe), que é erigida num cenário colaborativo internacional;

d) a CLEP, sendo uma coleção de investigação, não é uma antologia, embora padeça de critérios de seleção: exclusão e integração. A consciência deste poder legitimador refletiu-se no próprio processo de pesquisa.

\subsection{Processo de Investigação}

Inicialmente, pareceu-me imperativo ter um número de obras/entradas selecionadas para começar a coleção, já que se trata de um recurso online com uma visualização instantânea - penso que este será o processo mais comum, já que estamos habituados, pela herança da cultura impressa, a lidar com a publicação de obras acabadas, avaliando, sobretudo no campo da investigação, o que se encontre finalizado, mesmo quando está online. Tipicamente, na área das ciências humanas, por oposição às ciências naturais, apavora-nos o incompleto, o que está ainda em processo e, sobretudo, o erro. Talvez quem edite uma coleção não reconheça de imediato que se trata de uma coleção de pesquisa, de um projeto que se vai, por esse motivo, desenvolvendo - até porque sempre que uma entrada de um autor, obra, editora, etc. não existe, é necessário criá-la -; um projeto que cresce com cadência, organicamente, que está exposto ao engano, a ser expandido, a ser cortado, apagado, enfim, editado em tempo real. Assim, cedo abandonei o temor da incompletude.

Por outro lado, este carácter editável permite que a coleção que existiu no final de Agosto de 2013 não seja em nada semelhante àquela que existiu no início de

\footnotetext{
${ }^{3}$ Desde o início do século 20, a comunicação de movimentos artísticos e literários entre autores e países tem vindo a ser cada vez menos desfasada (em Portugal, a exceção foi o despontar tardio do Surrealismo). De facto, o movimento da poesia concreta e experimental pode ser visto como o primeiro grande movimento global. Atualmente, para além da literatura eletrónica, o movimento da literatura conceptual é outro desses fenómenos.
}

Texto Digital, Florianópolis, Santa Catarina, Brasil, v. 11, n. 1, p. 387-419, jan./jun. 2015. ISSNe: 1807-9288. 
Setembro, àquela que existiu durante a primeira análise, em Novembro, e àquela que existirá daqui a alguns meses ou anos, visto permanecer uma obra em construção. De igual modo, mesmo a própria análise da coleção que hoje faço comporta esse carácter de corte no tempo - uma visão de um instante no espaçotempo, uma secção mutável. Pretendo assim demonstrar que o processo em si não só foi surpreendente e pedagógico, como continuará a permitir-me descobrir obras e características não previamente concebidas.

Alicercei o processo de pesquisa para a construção da CLEP em diversas fontes já reunidas nas bases de dados da PO.EX e da ELMCIP, fundamentando-me, posteriormente, noutras obras criativas, ensaios e monografias que mais abaixo especificarei. Regressando aos critérios de seleção, prenderam-se e prendem-se sobretudo com a relevância histórica das obras, a sua recepção e resistência crítica, a sua influência e qualidade, o que, inevitavelmente, se enraíza também numa escolha pessoal. O corpus já considerável da CLEP permitiu, porém, que uma aturada leitura crítica pudesse encetar a sua marcha. Neste sentido, formularam-se uma hipótese e uma pergunta norteadora: será a herança do movimento experimental - refletida num experimentalismo recorrente - $\mathrm{e}$ a função transgressora da literatura que Ana Hatherly e E. M. de Melo e Castro referem opondo-se à ditadura, à censura, ao marasmo intelectual e artístico, e aos garrotes da liberdade - o que caracteriza a especificidade fundadora do contexto português no âmbito da literatura eletrónica? Que marcas distinguem, de facto, a ciberliteratura portuguesa?

\section{Sinopse da Coleção de Literatura Eletrónica Portuguesa}

Coleção de Literatura Eletrónica Portuguesa (CLEP)

http://elmcip.net/research-collection/portuguese-electronic-literature-collection

Editada por Álvaro Seiça

Colaboradores: Manuel Portela e Rui Torres 
A Coleção de Literatura Eletrónica Portuguesa (CLEP), na base de dados ELMCIP, pretende abordar e recolher as obras criativas e teóricas mais relevantes produzidas por autores portugueses no campo da literatura eletrónica, durante os últimos quarenta e cinco anos. A coleção agrega também autores, eventos, organizações, editoras, periódicos, publicações, conferências, performances, instalações e exposições que estejam relacionadas com o contexto português.

As primeiras obras de literatura eletrónica produzidas em Portugal lidaram essencialmente com literatura gerada por computador (LGC). As obras $A$ Literatura Cibernética 1: Autopoemas Gerados por Computador (1977) e A Literatura Cibernética 2: Um Sintetizador de Narrativas (1980), de Pedro Barbosa, podem ser consideradas as primeiras a combinar criação literária e programação computacional. Nestes volumes, para além de um enquadramento teórico, Barbosa publicou uma seleção dos resultados (poesia e ficção) dos seus geradores textuais, programados num computador de grande porte, percurso que desenvolveu noutros suportes e linguagens desde os anos 80 até hoje. Por sua vez, entre 1981 e 1983, Silvestre Pestana criou uma série de poemas cinéticos e visuais, Computer Poetry, usando, no entanto, um computador pessoal Spectrum. E. M. de Melo e Castro, pioneiro da videopoesia, e. g. Roda Lume (1968), realizou vários videopoemas com equipamento eletrónico, ao longo da década de 80 , e trabalhou com programas de edição de imagem, cunhando o termo "infopoesia" para descrever os seus trabalhos poéticos com meios informáticos. Para além do mais, tem vindo a teorizar vastamente sobre diversos aspectos do experimentalismo literário, da videopoesia e da infoliteratura.

Na produção contemporânea, é importante destacar autores como Antero de Alda e Manuel Portela, iniciando o seu percurso artístico no final da década de 80 no âmbito da poesia visual e, mais tarde, da poesia digital, salientando-se singularmente a obra teórica de Portela. A partir de 2000, há uma nova geração de criadores-programadores, como André Sier, artista digital que tem desenvolvido também algumas peças textuais, e Rui Torres, escritor cujo trabalho 
criativo e teórico, influenciado por Barbosa, se tem revelado decisivo não só na elaboração de poemas digitais combinatórios e em rede, mas também na divulgação do legado da PO.EX e da ciberliteratura no panorama dos estudos literários.

A edição da CLEP fundamentou-se em diferentes fontes: ensaios e monografias e. g. Poemografias: Perspectivas da Poesia Visual Portuguesa (1985), editada por Fernando Aguiar e Silvestre Pestana; Poética dos Meios e Arte High Tech (1988) de E. M. de Melo e Castro; A Ciberliteratura: Criação Literária e Computador (1996) de Pedro Barbosa; e Prehistoric Digital Poetry: An Archaeology of Forms, 1959-1995 (2007) de Christopher T. Funkhouser -, para além de bases de dados e arquivos digitais, como a ELMCIP KB e o PO.EX, beneficiando da colaboração de Manuel Portela e Rui Torres, investigador responsável do Arquivo Digital da Literatura Experimental Portuguesa.

Como registo complementar, a CLEP inclui uma video-entrevista a Manuel Portela e Rui Torres, gravada durante a conferência da Electronic Literature Organization 2013 "Chercher le Texte", em Paris, que interpela os autores em relação a algumas das características relevantes, influências e direções futuras da literatura eletrónica portuguesa.

\section{Um Feixe Luminoso: Uma Leitura da Coleção de Literatura Eletrónica Portuguesa}

Durante o século 20, vários autores portugueses assumiram uma posição bastante empolgante em relação às vanguardas literárias e artísticas, sobretudo no campo poético. A primeira fase de vanguarda foi introduzida pela geração futurista e modernista, ligada à revista Orpheu (1915), com Mário de SáCarneiro ${ }^{4}$, Fernando Pessoa, Almada Negreiros, Santa Rita Pintor, entre outros,

\footnotetext{
${ }^{4}$ É relevante repensar alguns dos poemas futuristas, e. g. "Manucure" (1915) de Mário de SáCarneiro, como parte de uma trajetória histórica da poesia visual que vem desde a Antiguidade Clássica até ao período barroco, de Mallarmé até Marinetti e Apollinaire, sendo renovada com a 
cuja redescoberta se deu com a geração da presença (1927-40), tida por alguns críticos como "segundo modernismo". Se bem que outros movimentos artísticos como o neo-realismo (anos 1930-50), o surrealismo e o abjeccionismo (anos 1940-60) - e grupos literários, associados geralmente a revistas ou antologias como Árvore (1951-53) e Poesia 61 (1961) -, tenham desencadeado novos modelos literários, assentes em novas preocupações estéticas, sociais e culturais, para além de rupturas na linguagem poética ${ }^{5}$, a segunda fase radicalmente vanguardista foi empreendida pelo movimento de POesia EXperimental (PO.EX) dos anos 1960. Esta clivagem aconteceu em parte como reação à fragmentação psicológica do sujeito modernista, à estética neo-realista e surrealista, ${ }^{6}$ ao contato com as correntes artísticas internacionais, mas também como oposição criativa e crítica à guerra colonial, iniciada em 1961, e à ditadura e censura oprimindo o país.

Com a publicação dos cadernos antológicos Poesia Experimental 1 (1964), organizado por António Aragão e Herberto Helder, e Poesia Experimental 2 (1966), organizado pelos mesmos autores e E. M. de Melo e Castro, estabeleceuse um movimento ativo de escritores, artistas e músicos, como António Aragão, Ana Hatherly, Herberto Helder, José-Alberto Marques, E. M. de Melo e Castro, Álvaro Neto (Liberto Cruz), Jorge Peixinho e Salette Tavares ${ }^{7}$. A heterogeneidade

literatura experimental dos anos 1960. Esta trajetória histórica de textos-imagens foi bem documentada, quer por E. M. de Melo e Castro (1965), quer por Ana Hatherly $(1975,1983,1985)$.

${ }^{5}$ Embora 2020 esteja ainda no futuro, como uma estaca temporal simbólica de releitura, assinalada por Melo e Castro acerca das vanguardas na poesia portuguesa do século 20 , a perspectiva revisionista de períodos vanguardistas que aqui exponho dialoga, de modo crítico, com o seu ensaio (1980).

${ }^{6}$ Como refere Pedro Reis: "PO.EX opposes the sentimentalism of traditional poetry in general and it rejects the rigidity of metrics and rhyme. On the other hand, it proposes the objectivity and collective work, in order to counterbalance a very much heavy heritage of psychological individualism that was typical of the Orfeu generation. It also suggests resistance and internationalism as a way of repudiating the nationalist Portuguese project, as well as it rejects the neo-realistic ideological speech and the surrealistic automatism, proposing in their place an approximation to a scientific approach." (2008, p. 27)

${ }^{7}$ Nestes cadernos colaboraram outros autores, como António Barahona da Fonseca (também ligado ao surrealismo), António Ramos Rosa (também ligado às revistas Árvore e Cassiopeia) e Luiza Neto Jorge (também ligada à Poesia 61), cujas obras intersectam o movimento, mas posteriormente seguem um percurso diferente; o mesmo pode ser dito da obra de Herberto Helder, contendo uma trajetória singular. Os cadernos incluíram uma antologia de autores relevantes para a estética experimental: de Ângelo de Lima a Mário Cesariny, de Luís de Camões a Quirinus Kuhlmann. 
destes autores, bem como a organização, por Melo e Castro, das revistas ${ }^{8}$ Operação 1 (1967) e Hidra 2 (1969), nas quais participam vários dos autores dos Cadernos de Poesia Experimental, mas também Silvestre Pestana, alargou o espectro da sua produção criativa, fazendo com que a noção do experimentalismo português não se resumisse, nem pudesse ser resumível, apenas à poesia concreta, mas, antes, a uma proliferação de vectores criativos com um carácter aberto e verdadeiramente "experimental", aglomerando práticas como a poesia visual, a poesia e arte conceptual, a "poesia fílmica", a poesia sonora, a "poesiaobjecto", a "acção poética" (ou happening) e a exposição. De facto, esta postura é desde logo vincada no primeiro editorial (“Introdução”) dos cadernos, referindo Herberto Helder: "Uma concepção unilateral de aventura anularia o princípio básico de busca individual e livre, já que liberdade é, tanto em sentido estético como moral, o primeiro dos signos - o da eficácia" $(1964$, p. 6).

Este movimento heterogéneo seria expandido e, dos anos 60 até final da década de 1980, entre novas revistas, antologias, publicações e exposições, os autores da PO.EX e António Barros, António Dantas, Emerenciano, César Figueiredo, Armando Macatrão, António Nelos, Silvestre Pestana, Alberto Pimenta, AbílioJosé Santos, Pedro Barbosa, Fernando Aguiar, Antero de Alda e Gabriel Rui Silva reavivaram as práticas experimentais, com recurso à performance, ao happening, à instalação, à ficção experimental, à poesia visual e sonora, à videopoesia, à literatura gerada por computador (LGC) e à infopoesia (poesia eletrónica). Por conseguinte, é no âmbito da PO.EX que se deve sinalizar e compreender as raízes da ciberliteratura portuguesa.

\footnotetext{
De referir que os cadernos publicaram igualmente alguns dos autores estrangeiros que influenciaram e foram influenciados pela criação portuguesa, difundindo em Portugal o seu trabalho, como os poetas concretos brasileiros Haroldo de Campos, Pedro Xisto e Edgard Braga, os espacialistas e poetas sonoros franceses Pierre Garnier e Henri Chopin, o poeta italiano Emilio Villa e o escocês lan Hamilton Finlay. Já anos antes, a carta de Melo e Castro publicada no The Times Literary Supplement (25/05/1962) sobre o grupo Noigandres havia despertado a curiosidade pela poesia concreta no Reino Unido, sobretudo em Edwin Morgan, também ele criador de "poemas eletrónicos", e lan Hamilton Finlay (2012, p. 272), entre outros.

${ }^{8}$ Estas revistas podem ser lidas e manipuladas digitalmente em http://po-ex.net/evaluation/. Este URL contém o material coligido no CD-ROM publicado pelo projeto de investigação "Poesia Experimental Portuguesa: Cadernos e Catálogos" (2005-2008), parte do arquivo PO.EX, coordenado por Rui Torres.
} 
Um dos primeiros pontos de atenção dado em Portugal à combinatória computacional enquanto proposta literária e ao "princípio combinatório [como] base linguística para a criação poética" foi o livro Electronicolírica (1964), de Herberto Helder, cuja complexa composição processual - após o regresso de Itália de António Aragão, veículo de vanguarda - foi influenciada, nas palavras do próprio autor, pelas experiências combinatórias com calculadora eletrónica de Nanni Balestrini, na sua série de poemas generativos Tape Mark 1 (1961) e Tape Mark 2 (1962). Não esqueçamos, porém, a multiplicidade de aproximações semelhantes neste período. O princípio combinatório matemático havia já sido abordado por Melo e Castro no poema "Soneto Soma 14x" (1963, p. 38) e, mais tarde, na própria estrutura do ensaio A Proposição 2.01: Poesia Experimental (1965). Ao mesmo tempo, António Aragão redistribuía palavras selecionadas de jornais no espaço da página, possibilitando inúmeras leituras recombinantes em "poesia encontrada" (1964), publicado em Poesia Experimental 1. O princípio aleatório, baseado num algoritmo de leitura, seria explorado por Salette Tavares no poema "al gar ismos alfinete" (1966), publicado em Poesia Experimental 2. Ana Hatherly, entre 1965 e 1970, recombinaria variações linguísticas, publicadas em Anagramático (1970), sendo que no seu extenso trabalho teórico nos lega a reavaliação de um conjunto de escritores do período barroco, pontuado por experiências combinatórias literárias e máquinas textuais visionárias.

Todavia, em 1975, o trabalho pioneiro de Pedro Barbosa introduz a literatura gerada por computador (LGC) em Portugal. Tendo trabalhado na Universidade de Estrasburgo com Abraham A. Moles, Barbosa publicou posteriormente três volumes teórico-práticos das suas experiências de programação com as linguagens FORTRAN e BASIC, que lidam com questões de combinatória e aleatoriedade, desenvolvendo algoritmos capazes de aliar computação e produção literária, na perspectiva de uma teoria do texto computacional. Como refere o autor, A Literatura Cibernética 1: Autopoemas Gerados por Computador (1977) trata "[d]o esboço de uma teoria, toda uma prática, dois métodos e dois programas, que irão facultar a qualquer leitor, interessado e imaginoso, a confecção de poemas automáticos à razão de 5200 versos por hora: no espaço 
intraorgânico de qualquer computador!" (p. 8). Os "auto-textos" de Barbosa, ou "autopoemas gerados por computador", abrem um novo campo da teoria literária no contexto português, o da confluência direta entre literatura e computação, entre escritor e programador. Os autopoemas foram programados na linguagem FORTRAN, ALGOL e NEAT, durante 1975/76 (programa Permuta, subprograma Iserve, e programa Texal $^{9}$, subprograma Aletor), num computador Elliot/NCR 4130 (máquina introduzida nos anos 60 no Reino Unido), com a colaboração de Azevedo Machado, engenheiro do Laboratório de Cálculo Automático (LACA) da Faculdade de Ciências da Universidade do Porto. Em A Literatura Cibernética 1, Barbosa compilou uma seleção dos resultados textuais gerados pelos seus programas: os poemas permutacionais e os poemas aleatórios. Por um lado, os poemas permutacionais incluem "Poema de Computador", "25 de Novembro", "Verão", "Silêncios", "Cansaço das Palavras" e as "trovas electrónicas", assim subintituladas ${ }^{10}$, "Porto" ${ }^{11}$ e "Aveiro" (8! = 40.320 permutações, 576 versos, tempo de execução: 6'54"), na qual se permutam os morfemas "na”, "da”, "sem”, "uma" e os lexemas "água", "ria", "tristeza" e "alegria". A cidade de Aveiro, famosa pelos seus canais de água, é retratada com os opostos "tristeza/alegria" e "água/ria", já que o substantivo "ria" funciona também como verbo, fazendo emergir o seu oposto, "mágoa", através do jogo relacional da rima com o substantivo "água". Por outro lado, os poemas aleatórios apropriam, remixam e reescrevem poemas de

\footnotetext{
${ }^{9} \mathrm{O}$ nome TEXAL é obtido deste modo: "Gera TEXtos a partir de palavras / frases escolhidas ALeatoriamente dentre conjunto dado." (BARBOSA, 1980, p. 81)

${ }^{10}$ Há uma linha temática que, embora diferente no tratamento, perpassa três autores: Helder, Barbosa e Melo e Castro. Esta linha associa a ideia de construção lírica à máquina eletrónica e seria, no dizer de Melo e Castro (1994), recuperando A. Moles, o "mito dinâmico" da máquina poética criadora. Helder publica Electronicolírica em 1964, renomeando mais tarde o livro como "A Máquina Lírica"; alguns dos poemas de Barbosa são designados "trovas electrónicas", em 1977; Melo e Castro titula um dos seus livros Máquinas de Trovar (2008), estabelecendo-se uma ponte entre poesia lírica, trova e uma máquina capaz de produzir versos eletrónicos. A trova, quadra rimada de sete sílabas, forma antiga do séc. 13, surge como que refeita conceptualmente pelo computador no séc. 20. É uma constante: o autor quer o novo, mas rebusca uma forma ou um conceito tradicionais.

${ }^{11} \mathrm{~A}$ análise de Christopher Funkhouser atesta a natureza, quer composicional, quer simbólica, deste poema: "Porto, a city built on steep granite cliffs on the coast of Portugal, is the inspiration for the language presented and rearranged by the author for poetic effect. (...) Barbosa's program, while certainly cyclical ( ...) enables 40,320 permutations [and the] addition of prepositions adds three times as many configurations and prevents the poem from reflecting a slot apparatus" (2007, p. 40). E continua: "(...) the overall effect that is achieved by Barbosa's program is that endless different phrases are built that transmit different dimensions of the same sentiment (...) [a] sense of the passage of time (...) [and] other cultural aspects of the city and its people may be read into the lines, some of which nearly defy interpretation" (p. 41).
}

Texto Digital, Florianópolis, Santa Catarina, Brasil, v. 11, n. 1, p. 387-419, jan./jun. 2015. ISSNe: 1807-9288. 
outros poetas. Encontra-se neste grupo a série "Transformação", incluindo "Camões e As Voltas que o Computador (Ihe) Dá", que reescreve um texto renascentista ("clássico") com diversas transformações aleatórias de Os Lusíadas (1572), de Luís de Camões, e "É Preciso Dizer...", uma apropriação e recriação do poema surrealista ("contemporâneo") "Exercício Espiritual” (1956), de Mário Cesariny, no qual Barbosa alarga a prática irónica e surrealista do léxico inicial de substantivos. O que ressalta das versões resultantes dos poemas, para além do rigor sintático atingido e do minucioso trabalho codificador, é uma marca luminosa de crítica, ironia e paródia, quer ao estado vigente da literatura oficialmente canonizada, quer, sobretudo, ao clima de opressão e "medo" infligido pela longa ditadura, que ainda se fazia sentir. Contudo, questionar a perpetuação da "mentira" política, social e cultural mostrava-se o caminho passível de ser renovado pela recente instauração da democracia portuguesa - a "história" como continuidade e "revolução", no confronto entre ser humano e máquina.

Em A Literatura Cibernética 2: Um Sintetizador de Narrativas (1980), Pedro Barbosa defende a mesma perspectiva analítica da máquina literária que havia iniciado no primeiro volume. Influenciado por Max Bense e Abraham Moles, o autor desenvolve a ideia de "texto artificial", que mais tarde seria contestada por E. M. de Melo e Castro (1987), no sentido que a sua postura transmedial considera que todo o texto, produzido ao longo dos tempos com o auxílio de instrumentos tecnológicos diversos, será sempre artificial. Neste segundo volume, consagrado ao campo da ficção, Barbosa publica um sintetizador de narrativas, incidindo no conceito de "texto-matriz" como grelha transformável pelo programa. Tendo consciência que no domínio ficcional há uma procura por uma coerência semântica e narrativa, o autor publica os resultados mais interessantes das variantes das séries "Era Uma Vez...", "Fábulas", "Histórias dum Baralho de Cartas" e, por fim, "História dum Homem Citadino", cuja recepção literária tem sido mais explorada, e. g. Christopher Funkhouser (2007) e Roberto Simanowski (2011), que curiosamente a leu como um poema ${ }^{12}$.

\footnotetext{
${ }^{12}$ Simanowski refere que Barbosa "deconstruct[s] its form by running it through his text generator. (...) The outcome is predictably absurd and humorous, and portrays wild deviations from the mundane occurrences found in the original. Applying the chance procedures of a text generator to
}

Texto Digital, Florianópolis, Santa Catarina, Brasil, v. 11, n. 1, p. 387-419, jan./jun. 2015. ISSNe: 1807-9288. 
Fechando a trilogia teórico-prática, podemos dizer que Máquinas Pensantes: Aforismos Gerados por Computador (1988) pode ser visto como o terceiro volume de $A$ Literatura Cibernética. Aqui, o autor apresenta uma longa série de aforismos literários, em que a geração de textos é referida como "assistida por computador" (Literatura Assistida por Computador) em linguagem BASIC. A série " $A$ " (programa Re-text) lida com "re-textualizações" (BARBOSA, 1988, p. 59) combinatórias de um fragmento ("texto-matriz") de Nietzsche e a série "B" (programa Acaso), que havia sido publicada parcialmente no Jornal de Notícias (1984), inspira-se no modelo conceptual criado por Melo e Castro $^{13}$ no poema "Tudo Pode Ser Dito Num Poema", incluído no livro Álea e Vazio $(1971)^{14}$. Por último, a série "C" (programas Afor-A e Afor-B) compreende reformulações de aforismos portugueses tradicionais, que resultam em novas leituras, ora irónicas, ora surrealistas. Uma característica que realça a importância da programação, para Pedro Barbosa, é o facto de publicar na secção final de cada um dos três volumes o código fonte dos programas utilizados, o que hoje comporta um carácter arqueológico valioso, de livre acesso, na medida em que documenta a prática codificadora e possibilita futuras análises criativas e críticas.

A sua experimentação com novos geradores textuais continua nos anos 90 , quando cria, com a programação de Abílio Cavalheiro, o SINtetizador TEXTual "SINTEXT" (1992-95) no sistema operativo DOS (BARBOSA, 2013, n.p.), sendo posteriormente adaptado para a Web, "Sintext-W" (1999), com a colaboração de José Manuel Torres. "Sintext" é um gerador polivalente, permitindo a interferência com outras bases de dados literárias, do autor e não só, como a recriação de "A

this poem inevitably subverts the status quo of his subject. It spices up the boring life of the city man by turning the depressing poem into seasoned surrealist lines. The form of the computergenerated text responds to the chosen content of the database. The result seems to declare that there is no other chance than accepting the chance. (...) Although the content of the outcome is owned by the machine, the meaning belongs to the human behind it (...)" (2011: 102-103).

${ }^{13}$ Será o próprio Melo e Castro quem assinará uma precoce recensão aos aforismos, na revista Colóquio Letras (1986), revelando-os como inegáveis produções literárias.

${ }^{14}$ Note-se que Rui Torres (2014), colaborando com Nuno F. Ferreira na reprogramação em JavaScript do programa Poemário.js, recentemente "retextualizou" em XML, na esteira de Barbosa, alguns dos poemas de Álea e Vazio: http://184.154.160.228/taxonomia/materialidades/digitais/e-m-de-melo-e-castro-alea-e-vazioretextualizacoes 
Máquina de Emaranhar Paisagens" (1964) de Herberto Helder. É ainda a partir do "Sintext" que Barbosa gera automaticamente os textos da sua ópera eletrónica, ou "quântica", AlletSator (2001). Mais tarde, em colaboração com Luís Carlos Petry, - libreto transforma-se numa peça interativa 3D, sobre a qual a revista Cibertextualidades dedicou o seu segundo número, "Ciberdrama e Hipermédia" (2007), com diversas aproximações teóricas e um CD-ROM da obra AlletSator v4.5. A par da atividade criativa, Barbosa manteve sempre um sólido registo ensaístico, tendo completado nos últimos anos algumas monografias, das quais se destaca A Ciberliteratura: Criação Literária e Computador (1996), que estabelece teoricamente o seu percurso, bem como as linhas de pesquisa da ciberliteratura, expondo o estado da arte literária em ambiente computacional.

Nos anos 1980, porém, dá-se a introdução dos computadores pessoais (PCs). Enquanto que a primeira etapa criativa de Barbosa utilizou um computador de grande porte, apenas acessível num ambiente institucional, o contexto em que Silvestre Pestana cria os seus primeiros poemas de computador ${ }^{15}$ é totalmente diferente, numa nova vaga à qual Barbosa nomeia "poesia doméstica" (1996, p. 147). Com recurso a computadores pessoais, Silvestre Pestana programou em BASIC, primeiro num Sinclair ZX-81, e, depois, já com iluminação cromática, num Sinclair ZX Spectrum, três poemas dedicados respectivamente a Henri Chopin, E. M. de Melo e Castro e Julian Beck, que formam a série Computer Poetry (198183). Pestana, artista visual, escritor e performer, tendo regressado no pós-25 de Abril de 1974 do exílio na Suécia, trouxe consigo influências diversas que ativou quer no suporte fotográfico e videográfico, quer na performance e no suporte informático. De entre a sua produção, interessa-me realçar a peça conceptual emblemática Povo Novo (1975), que é reencetada pelo próprio autor na referida

\footnotetext{
${ }^{15}$ A poesia programável em suportes eletrónicos tem tido várias designações, consoante o autor, o período de criação ou teorização e a língua. A diversidade é estonteante: desde a popularização, nos anos 60 e 80 , da expressão computer poetry e computer poem (poema de/criado em computador), em paralelo com a computer art, até poésie générée/assistée par ordinateur (poesia gerada/assistida por computador) e poésie numérique (poesia numérica), passando por ciberpoesia, infopoesia, new media poetry, electronic poetry ou e-poetry (poesia eletrónica), termo que se generalizou durante a década de 1990 e 2000, a par de digital poetry (poesia digital). Para uma discussão detalhada deste aspecto, leia-se o ensaio "E-CyberDigital Poetry" (SEIÇA 2014).
}

Texto Digital, Florianópolis, Santa Catarina, Brasil, v. 11, n. 1, p. 387-419, jan./jun. 2015. ISSNe: 1807-9288. 
série de poemas visuais cinéticos ${ }^{16}$, ou "infopoemas" (MELO E CASTRO, 1988, p. 57). Operando quase como scripts televisivos, a série oscila entre formas reconhecíveis - como a oval e o letrismo animado de maior dimensão, construído pelas pequenas palavras "ovo", "povo", "novo", "dor" - e a leitura interpretativa das próprias palavras: "ovo" (a unidade, mas também a potência), "povo" (o coletivo, indistinto, as massas), "novo" e "dor". Este jogo de relações traduz a nova consciência, embora dolorosa, de um "novo povo" para uma nova época histórica, social e artística, a da liberdade e do ato. Pestana afirmou, em entrevista (2011), ter pesquisado mais de trinta línguas, mas só em português encontrara a possibilidade de percorrer o singular e o plural, o indivíduo e o coletivo, o passado, o presente e o futuro, apenas com a deslocação de uma letra: ovo/(p)ovo/(n)ovo.

O facto de a consola do Spectrum se ligar a um televisor, dispositivo visual e lumínico por excelência, acabou por ter também um significado simbólico, na medida em que Computer Poetry ficou associado não só ao conteúdo, mas também à capa de uma das coletâneas mais importantes da década de 80 , Poemografias: Perspectivas da Poesia Visual Portuguesa (1985). Apesar de ser uma coletânea de poesia visual, não foi utilizada nenhuma impressão da obra para a composição da capa, mas, antes, a fotografia da imagem da obra num ecrã televisivo, ou seja, uma imagem da imagem em movimento, como nos conta Fernando Aguiar, que co-organizou a antologia com o próprio Pestana:

\begin{abstract}
Desenhei a capa do livro com base num poema de computador do Silvestre Pestana (que tinha criado os primeiros computer-poems [sic] em 1981/83 num "Spectrum"). E se agora parece uma coisa quase banal, em 1985 foi realmente "diferente" apresentar uma antologia de poesia e de teoria poética com uma obra "gerada" por computador na capa. (Como não tínhamos acesso a impressora - nem sei se havia naquela altura alguma associada ao Spectrum - fomos a uma loja de electrodomésticos e pedimos para ligar o "computador" a uma televisão, e ali mesmo fiz várias fotografias de um dos poemas, das quais resultou a capa de "POEMOGRAFIAS". (AGUIAR, 2009, n.p.)
\end{abstract}

\footnotetext{
${ }^{16}$ Pestana chega a chamar-Ihes "video-computer-poetry" (1985, p. 205), numa clara referência à videopoesia que também criou nos anos 70 e 80.
}

Texto Digital, Florianópolis, Santa Catarina, Brasil, v. 11, n. 1, p. 387-419, jan./jun. 2015. ISSNe: 1807-9288. 
A luz, como princípio caracterizador ou despoletante da poética, manifesta-se fortemente na obra de E. M. de Melo e Castro, autor central na conjugação da textualidade, visualidade e sonoridade, mas também no uso de meios informáticos na criação literária. Tendo começado a sua experimentação poética nos anos 50, Melo e Castro viria - depois dos poemas de José-Alberto Marques (1958) e Ana Hatherly (1959) - a publicar o primeiro ${ }^{17}$ volume de poesia concreta em Portugal, Ideogramas (1962), sobre o qual Pedro Xisto, em carta de 4/11/1962, comentou: "São eles de ler? Não e sim. Pois não são de ler e ver? E ainda não e sim, que há mais. (...) Quem sabe, na poesia, isto é, no poema, há de se ler, ver, ter, verter um ser - o próprio ser do poeta, senão ( $\underline{\text { sim ou não?) o ser }}$ próprio do objecto. (...) O certo é que funciona o gerador - a máquinaimagem." (sublinhados do autor)

Como explica Melo e Castro, "Concrete Poetry in 1960 was for me not an arriving point but rather a launching platform." (2007, p. 180) Esta afirmação reflete o percurso eclético da sua obra, que se expande por diversas áreas literárias e artísticas há mais de sessenta anos. Contudo, serão os domínios da sua obra que abrangem a videopoesia e a infopoesia nos quais me irei focar, dado que estão

\footnotetext{
${ }^{17}$ Tem havido alguma divergência na atribuição da maternidade ou paternidade do primeiro poema concreto publicado em Portugal, se é que tal discussão, se não apenas pela atestação de uma cronologia factual, tem realmente interesse, quando se constata que diversos autores estavam a travar uma ruptura criativa no sistema literário num período muito próximo. Apesar de E. M. de Melo e Castro reclamar nas badanas de diversos livros o epíteto "introdutor em Portugal da Poesia Concreta (1961)" (e. g. 1996, 1998) - e de facto, genericamente, se atribuir a si a introdução da poesia concreta, dado que publicou a primeira recolha de poemas concretos, e a Ana Hatherly a introdução teórica, com o artigo "O Idêntico Inverso ou o Lirismo Ultra-Romântico e a Poesia Concreta", e anexo "primeiro poema concreto" (1959), publicados no Diário de Notícias -, a verdade é que o próprio José-Alberto Marques, relegando a questão para Haroldo de Campos, corrobora a paternidade com a publicação do poema "Solidão" (1958), com o subtítulo "poema concreto", na revista do Colégio Andrade Corvo, em Torres Novas (original reaparecido na exposição antológica do movimento experimental em Serralves, 1999). Esta posição, que para uns parece clara, mas, para outros, mesmo quando a admitem, suscita dúvidas ou não é exposta como pioneira, não deixa contudo de suster as marcas visuais ou experimentais já presentes nas obras Poemas Propostos (1954), de Jaime Sampaio, referido por Aguiar (2006), ou Espelho Cego (1957), de Salette Tavares, referido por Rui Torres (2008), para além da obra de Alexandre O'Neill, entre outros. Mais ainda, se considerarmos a obra La Dame de Coeur (1940) de Maria Helena Vieira da Silva, podemos afirmar que esta pintura-colagem sobre tipografia concreta batida à máquina de escrever é a primeira obra de poesia concreta em Portugal. Vieira da Silva combina as letras $A, M, O, R$ e $V, I, D, A$, com as quais cria as seguintes linhas: "AMOR VIDA VIVA", "VIVA A ROSA VI" e "A VIVA A VIDA". A obra é uma intervenção lúdica com a carta "dama de copas", sendo que a "dama" é apelidada com pontos de interrogação entre os nomes IRACEMA, VIRGINIA, CLARA e LAURA.
}

Texto Digital, Florianópolis, Santa Catarina, Brasil, v. 11, n. 1, p. 387-419, jan./jun. 2015. ISSNe: 1807-9288. 
relacionados com a produção criativa em ambiente eletrónico ou computacional. Melo e Castro escreveu poesia em diversos suportes físicos - o caminho do "peso pesado do átomo" (citado por Cruz 2006) -, como o papel, o têxtil, a tela, a madeira, o metal, a pedra, o plástico, cedo optando por uma desmaterialização da palavra e da imagem, algo que se tornou patente, desde logo, no seu videopoema pioneiro Roda Lume (1968). Esta desmaterialização da obra de arte serviu de fio condutor para a exposição retrospectiva "O Caminho do Leve" (2006), no Museu de Arte Contemporânea de Serralves, no Porto. Segundo Melo e Castro,

\begin{abstract}
When I began using video technology to produce my first videopoem, Roda Lume (Wheel of Fire), in 1968, I did not know where the limits were and where my experiments would take me. I was really experimenting on the most elementary meaning of the word experience. A sense of fascination and adventure told me that the letters and the signs standing still on the page could gain actual movement of their own. The words and the letters could at last be free, creating their own space. (2007, p. 176)
\end{abstract}

Roda Lume - videopoema com a duração de 2' 43" que foi transmitido pela Rádio Televisão Portuguesa (RTP) em 1969 e destruído posteriormente pela própria emissora, tendo sido refeito por Melo e Castro, em 1986, a partir do guião original - é, de facto, surpreendente, como poema que une as valências de texto, texto cinético, imagem, imagem em movimento e som, antecipando e influenciando vários géneros de poesia digital hipermédia realizada sobretudo a partir do aparecimento da World Wide Web. Por outro lado, conforma uma noção diferente de espaço-tempo, abrindo um "tempo visual" (MELO E CASTRO, 1993, p. 238) de desdobramento da imagem e do texto, que acarreta uma nova percepção de leitura.

Numa segunda fase, entre 1985 e 1989, Melo e Castro desenvolveu outro projeto de videopoesia, Signagens - nos estúdios da Universidade Aberta, em Lisboa -, no qual remediou algumas das suas obras concretas iniciais, criando também novos poemas, introduzindo cor com imagens geradas por computador, como, por exemplo, em Ideovídeo (1987), Poética dos Meios (1988) e Vibrações Digitais Dum Protocubo (1988). Numa terceira fase, produzida já num estúdio doméstico, deve-se salientar a série de cinco vídeos Sonhos de Geometria (1993), com 
música eletrónica do duo Telectu (Jorge Lima Barreto e Vítor Rua). A produção videopoética castriana, embora influenciada pela poesia concreta dos anos 195060 e pelo cinema de animação, desencadeia uma nova estética, no âmbito da animação de computador. Como afirma o próprio poeta, "inscreve-se naturalmente naquilo a que se pode chamar arte sinestésica em que o fascínio exercido através da vista encontra equivalentes nos outros sentidos principalmente nos seus aspectos somáticos" (MELO E CASTRO, 1988, p. 66).

Desde 1986, Melo e Castro trabalhou igualmente numa série de experiências com outros suportes informáticos, a que denominou "infopoesia", usando diferentes programas de edição de imagem. Mais uma vez - sendo um dado que Jorge Luiz Antonio (2001) não realça na sua análise -, a escolha predominante de editores de imagem, em detrimento de processadores textuais, revela a filiação visual da poética castriana. As animações de infopoemas visuais consideram o pixel como unidade principal de significado, na perspectiva de uma linguagem infopoética, tendo algumas das imagens sido publicados ${ }^{18}$ em Finitos Mais Finitos: Ficção/Ficções (1996) e Algorritmos: Infopoemas (1998), cujo ensaio inicial desenvolve "uma poética do pixel" e explica as amálgamas criadas no título. A busca pela transgressão, que surge no título do livro, é acompanhada pela busca de síntese formal:

a fixação em papel ou noutro suporte (...) dessas imagens virtuais que são energia luminosa, são apenas atualizações instantâneas de um momento da sua existência. São mesmo uma violência exercida pelo operador contra a natureza transformável e instável dos infopoemas, cuja razão será uma constante transformação, até atingirem o nível da síntese última de um único PIXEL branco numa tela branca. Branco sendo a síntese de todas as cores. LUZ. (MELO E CASTRO, 1988, p. 13)

Desde os anos 60, o autor publicou várias obras ensaísticas, das quais gostaria de salientar A Proposição 2.01 (1965), cimentando o caminho teórico da poesia experimental, As Vanguardas na Poesia Portuguesa do Século Vinte (1980) e

\footnotetext{
${ }^{18}$ Outro conjunto cromático de infopoemas, já da fase de laboração no Brasil, encontra-se disponível em http://www.ociocriativo.com.br/guests/meloecastro/frames_info.htm
}

Texto Digital, Florianópolis, Santa Catarina, Brasil, v. 11, n. 1, p. 387-419, jan./jun. 2015. ISSNe: 1807-9288. 
Literatura Portuguesa de Invenção (1983), em que relê e questiona diversos períodos da literatura portuguesa do ponto de vista de uma estratégia transgressora recorrente. Já em Poética dos Meios e Arte High Tech (1988), aborda diferentes suportes criativos e o tema da tecnologia, arte, ciência e literatura, focando-se nos géneros da infoarte (análise menos abrangente), infopoesia, videopoesia, holopoesia, telearte e robótica, considerando a existência de uma "estética fractal" e "poética de gravidade zero". Este volume reúne ensaios previamente publicados na imprensa, nos quais se encontra uma ampliação de “Infopoesia ou Poesia Informacional”, Diário de Lisboa (29/10/1987). Este artigo deve ser enfatizado, já que ajudou a definir o estado da arte da "poesia informática", expondo as linhas criativas dos anos 60 nas obras de Nanni Balestrini, Herberto Helder, Margaret Masterman e Marc Adrian, introduzindo igualmente novos autores portugueses e brasileiros, como Pedro Barbosa, Silvestre Pestana, Antero de Alda, Erthos Albino de Souza e João Coelho. Para além do mais, difundiu junto de um público generalista a relevância da programação computacional na produção literária, ao sublinhar que, para alguns autores, "a própria programação [é] o acto de criação poética por excelência, sendo o programa um poema" que faculta diferentes outputs (saídas). Como um feixe luminoso ${ }^{19}$ no contexto literário português, as diversas facetas da obra experimental de E. M. de Melo e Castro e a sua ampla divulgação revelaram-se decisivas, também, pela influência nas gerações futuras.

O panorama português contemporâneo é indubitavelmente marcado por Rui Torres, um escritor cuja obra eletrónica emergiu na primeira década do século 21. O seu trabalho teórico e criativo tem-se demonstrado crucial na disseminação da ciberliteratura (o campo "marginal izado" [sic], SARAIVA 1980, apud TORRES 2008) dentro dos estudos literários. Por um lado, Torres é o investigador principal

\footnotetext{
${ }^{19}$ Apesar de o título deste ensaio ter sido pensado inicialmente como "um feixe de luz", pela relevância da "luz" e da imaterialidade em diversas obras portuguesas, foi posteriormente alterado para "um feixe luminoso", por outro motivo adicional: a expressão $i$ punti luminosi (os pontos luminosos) - título da entrevista de Haroldo de Campos a Ezra Pound (1960) - é resgatada por E. M. de Melo e Castro na exposição antológica, e respectivo catálogo (2006), para descrever a sua trajetória literária e artística. Com a expressão "um feixe luminoso" reformulo, na minha perspectiva, a leitura de um percurso pela CLEP que une várias obras eletrónicas (pontos luminosos).
} 
do arquivo digital PO.EX, que tem sido responsável por inventariar, documentar, pesquisar e difundir o conhecimento sobre a literatura experimental portuguesa, tanto no território nacional como na rede internacional de literatura eletrónica. Por outro lado, a sua atividade criativa tem lidado essencialmente com práticas combinatórias programáveis, reapropriação ("plagiotropia", TORRES, 2012, n.p.) e remistura de textos literários existentes, quer portugueses (Raul Brandão, Florbela Espanca, Fernando Pessoa, Herberto Helder, Sophia de Mello Breyner e Salette Tavares), quer brasileiros (Clarice Lispector) e norte-americanos (Edgar Allan Poe), criando em XML, ActionScript e Flash obras poéticas generativas, assentes em bases de dados textuais online, que podem ser recombinadas pelos leitores/utilizadores e publicadas no Poemário, o seu weblog. O Poemário, que é também o nome do programa criado colaborativamente com Nuno F. Ferreira, gera o script dos poemas. Os poemas digitas de Rui Torres - como Mar de Sophia (2005), Amor de Clarice (2005), Húmus Poema Contínuo (2008), Poemas no Meio do Caminho (2008, obra vencedora do $4^{\circ}$ prémio de literatura digital Ciutat de Vinaròs), Um Corvo Nunca Mais (2009) e 8 Brincadeiras para Salette Tavares (2010) - refletem uma forte preocupação intertextual, para além de produzirem diferentes camadas de significantes e significados com o auxílio de som, texto animado e imagem dinâmica, em jogos cromáticos acentuados. Os seus poemas continuam uma linha programática de prática experimental e transgressão artística, na esfera de uma renovação criativo-crítica, que seguramente pode ser postulada em conjunto com a obra de E. M. de Melo e Castro, Silvestre Pestana, Pedro Barbosa e Manuel Portela.

Desde que algumas das obras de Torres foram selecionadas para coleções e antologias de literatura eletrónica - como Amor de Clarice e Poemas no Meio do Caminho, incluídas na Electronic Literature Collection 2 (2011), e PoemAds: Sob o Signo da Devoração $(2011)^{20}$, incluída na ELMCIP Anthology of European Electronic Literature (2012) -, a sua repercussão internacional e recepção crítica

${ }^{20}$ Esta obra de poemas-colagem é reminiscente de "Poesia Encontrada" (1964) de António Aragão, ao criar novos poemas com material encontrado, neste caso os slogans publicitários. Note-se que Rui Torres havia já feito, numa das releituras digitais em ActionScript dos poemas experimentais, a recriação da obra de Aragão, em Poesia Encontrada (2007), mas com feeds RSS da imprensa nacional e estrangeira.

Texto Digital, Florianópolis, Santa Catarina, Brasil, v. 11, n. 1, p. 387-419, jan./jun. 2015. ISSNe: 1807-9288. 
tem-se fortalecido, com diversos estudos no Brasil, Estados Unidos da América e Europa, e integração nos curricula universitários.

Manuel Portela marca, de igual modo, a mais recente atividade criativa e teórica no âmbito da literatura eletrónica. Para além da poesia visual dos anos 80 e 90, e de uma produção transmédia recentemente reunida na exposição antológica "escreler: 1988-2013" (2013), Portela tem desenvolvido uma prática criativa no âmbito da literatura eletrónica, com, por exemplo, o poema performativo Google Earth: A Poem for Voice and Internet (2009-11), apresentado no festival de poesia digital E-Poetry 2011. O poema coloca ironicamente em confronto a posição do indivíduo face à fragmentação discursiva contemporânea exercida pelo sistema geopolítico e económico (leitura de fragmentos de discursos políticos) e pela globalização (des)iluminada das tecnologias digitais (imagens de satélite em movimento, produzidas com o Google Earth). Desde meados de 2000, no plano teórico, Portela tem-se dedicado ao campo das materialidades da literatura, focando-se na literatura digital. Criou o portal eletrónico DigLitWeb (2005-2013), contendo numerosos recursos na área, integrou o projeto de investigação PO.EX' 70-80, coordena o arquivo digital (LdoD) do Livro do Desassossego, de Bernardo Soares/Fernando Pessoa, e tem vindo a publicar diversos ensaios sobre os processos de leitura e criação.

Como última nota indicativa no campo da criação eletrónica, deve-se ter em conta o percurso de Antero de Alda, numa linha continuadora da sua poesia visual dos anos 80 (o seu trabalho aparece em Poemografias), remediada no suporte digital na série cinética Gifpoemas (2003-), mas encontrando já as possibilidades expansivas da poética hipermédia programada nas séries Flashpoemas (2004-) e Scriptpoemas (2005-). Esta e, sobretudo, as mais recentes, criadas em JavaScript, contêm dezenas de poemas que abordam revisões críticas e irónicas da história da humanidade e do contexto político português e internacional. Outro caso, já esteticamente original, é o de André Sier, artista digital de cujas peças me ocupei noutros ensaios (SEIÇA 2011, 2012), que tem construído uma coerente, complexa e distinta obra na área da net.art, do código artístico e da instalação 
interativa, para além de algumas obras com elementos textuais que podem ser lidas na intersecção de vários campos e que, não criando novas estruturas literárias per se, problematizam contudo a definição de literatura eletrónica, e. $g$. CsO (2008) e 410 (2010).

Atualmente, em Portugal, as principais unidades de investigação sobre literatura eletrónica estão situadas: no Porto, na Universidade Fernando Pessoa, através do CETIC (Centro de Estudos sobre Texto Informático e Ciberliteratura), fundado por Pedro Barbosa e coordenado por Rui Torres (2003-07), e do CECLICO (Centro de Estudos Culturais, da Linguagem e do Comportamento), no qual Torres fundou e dirige, desde 2006, a publicação anual Cibertextualidades; em Coimbra, na Faculdade de Letras da Universidade de Coimbra, através do CLP (Centro de Literatura Portuguesa), que publica a Revista de Estudos Literários e a revista de livre acesso Mat.Lit, tendo igualmente lançado o programa de doutoramento "Estudos Avançados em Materialidades da Literatura", coordenado por Manuel Portela. Há também diversos centros de investigação que têm feito pesquisa na área, como o CECL (Centro de Estudos de Comunicação e Linguagens) da Faculdade de Ciências Sociais e Humanas da Universidade Nova de Lisboa, para além de outros centros espalhados pelo país, que intersectam, de um modo mais geral, arte e tecnologia. Recentemente, quer Manuel Portela (2013), quer Rui Torres (ed. com BALDWIN, 2014), deram à estampa duas importantes monografias em língua inglesa, que valorizam a produção ciberliterária portuguesa, ao situá-la no contexto internacional da literatura eletrónica.

\section{Expandindo o Horizonte}

Tentando proceder a um estudo tão vasto como aquele a que se propõe a CLEP, ou seja, uma coleção expansível erigida e hospedada numa base de dados literária online, a minha resposta passou por analisar as suas principais obras, lendo-as no âmbito de um fio histórico marcado por um experimentalismo literário diversificado nas suas propostas, mas que no entanto não deixa de caracterizar e distinguir a produção ciberliterária portuguesa. 
A ruptura introduzida pela PO.EX nos anos 1960 manifesta-se, deste modo, no campo atual da literatura eletrónica, através de um experimentalismo literário constante. Mais ainda, o carácter transgressor da linguagem e do ato criativo que foi um dos motores e condições da recusa do ambiente político da ditadura, da censura e da repressão social e artística - revela-se como uma luz presente:

\begin{abstract}
(...) funcionar como uma campanha de desmistificação dum discurso retrógrado que então parecia querer dominar um largo sector das nossas letras, em reflexo dum meio que vivia ancorado na acomodação e no marasmo (...), a sua acção era violenta: era não só um acto de rebeldia contra um status quo mas também um questionar profundo da razão de ser do acto criador (HATHERLY, 1985, p. 15)
\end{abstract}

Por outro lado, a minha análise centrou-se no conceito de luz como revelador de uma estética de vanguarda e como elemento conceptual unificador de várias obras, pela desmaterialização da palavra e da imagem proporcionada pelos suportes eletrónico-digitais. A leitura da CLEP como um feixe luminoso é, certamente, uma referência a um atributo imaterial comum - a obra de arte tendeu e continua a tender para a desmaterialização, tal como um feixe luminoso, que é visível, mas impalpável.

Embora alguns géneros de literatura eletrónica predominem no cenário português, como a infopoesia/poesia digital, enquanto outros escasseiem - ou não tenham tido repercussão representativa -, sobretudo no campo da ficção, como a ficção hipertextual (hiperfição) e a ficção interativa; e mesmo havendo ainda poucos (ou "marginal izados") escritores de obras digitais, a verdade é que os autores aqui tratados criaram obras densas, expressivas e diversificadas ao longo de mais de quarenta e cinco anos. Este dado comprova quantitativa e qualitativamente o valor literário e artístico da criatividade nesta área. Além disso, a prevalência da poesia também representa um facto invulgar, quando comparando com outras comunidades e países, em que a fiç̧ão domina o discurso.

Considerando que é ainda prematuro fazer uma análise com pretensões demasiado assertivas das obras dos últimos quinze anos, quanto mais uma 
narrativa historiográfica precisa, ou sequer um apanhado justo das práticas mais recentes, o espectro da minha leitura pode também ser interpretado como princípio metafórico - um feixe simbólico de um corpus literário que deverá expandir o nosso horizonte de preocupações criativas e aproximações teóricas.

\section{Agradecimentos}

Gostaria de agradecer a todos os que apoiaram a iniciativa da CLEP e a sua análise, especialmente a Scott Rettberg, pelo incentivo e sugestões, a Rui Torres, pela entrevista, referências disponibilizadas, digitalização de obras do projeto PO.EX e pela leitura e sugestões de revisão, a Manuel Portela, pela entrevista e incentivo, a Anders Løvlie, pela leitura preliminar e sugestões de revisão, e a Pedro Barbosa, pelos esclarecimentos e materiais fornecidos. Finalmente, a todos os autores da CLEP pelas suas obras, que inspiraram o meu trabalho.

\section{A LUMINOUS BEAM: READING THE PORTUGUESE ELECTRONIC LITERATURE COLLECTION}

ABSTRACT: The Portuguese Electronic Literature Collection (PELC) at the ELMCIP KB aims to address and collect the most relevant creative and critical works produced by Portuguese authors in the field of electronic literature during the past forty-five years. The collection also brings together authors, events, organizations, publishers, journals, publications, conferences, performances and exhibitions related to the Portuguese context. This paper critically examines PELC by focusing on literary, political, historical, aesthetic and technological elements through a common thread represented by a "luminous beam". It intends to highlight not only the thematic and medial transition and continuity, but also the transgression and rupture, that runs from the Portuguese avant-garde movement of Experimental Poetry from the 1960s to current electronic literature environments. Throughout the paper there is an analysis of several works by Pedro Barbosa, E. M. de Melo e Castro, Silvestre Pestana, Manuel Portela and Rui Torres.

KEYWORDS: Portuguese Electronic Literature Collection. Portuguese Experimental Literature. PO.EX. Videopoetry. Digital Poetry.

\section{Referências}

AGUIAR, Fernando. O Experimentalismo Poético em Portugal. O Eixo e a Roda, Belo Horizonte, v. 13, p. 111-118, 2006. <http://www.letras.ufmg.br/poslit> Acedido: 15/01/2014.

. Poéticas Experimentais. O Contrário do Tempo, s. p., 30 de Setembro de 2009. <http://ocontrariodotempo.blogspot.pt/2009/10/poeticas-experimentais-fazeste-mes-26.html> Acedido: 20/11/2013. 
AGUIAR, Fernando e Silvestre PESTANA (eds.) Poemografias: Perspectivas da Poesia Visual Portuguesa. Lisboa: Ulmeiro, 1985.

ALDA, Antero de. Gifpoemas. Online, 2003.

<http://www.anterodealda.com/gifpoemas.htm> Acedido: 22/01/2014.

. Flashpoemas. Online, 2004.

<http://www.anterodealda.com/poemasflash.html> Acedido: 09/11/2013.

Scriptpoemas. Online, 2005.

<http://www.anterodealda.com/scriptpoemas.htm> Acedido: 09/11/2013.

ANTONIO, Jorge Luiz. Um Conceito de Infopoesia. Online, 2001.

<http://www.pucsp.br/ cimid/4lit/antonio/infpoe.htm> Acedido: 11/11/2013.

. Procedimentos Poéticos Com o(s) Computadores. Experimental Poetics and Aesthetics, v. 0, s. p., 2010. <http://experimentalpoetics.com/blog/processospoticos> Acedido: 15/11/2013.

ARAGÃO, António. Poesia Encontrada. In ARAGÃO, António e Herberto HELDER (org.) Poesia Experimental, Lisboa, Cadernos de Hoje, v. 1, p. 37-42, 1964.

ARAGÃO, António e Herberto HELDER (org.) Experimental, Lisboa, Cadernos de Hoje, v. 1, 1964.

ARAGÃO, António, Herberto HELDER e E. M. de MELO E CASTRO (org.) Poesia Experimental, Lisboa, Cadernos de Hoje, v. 2, 1966.

ATHAYDE, Manaíra. No Laboratório das Palavras com Ernesto de Melo e Castro. Materialidades da Literatura, s. p., 14 de Outubro de 2012. <

http://matlit.wordpress.com/2012/10/14/no-laboratorio-das-palavras-com-ernestomelo-e-castro/> Acedido: 11/11/2013.

BALESTRINI, Nanni. Tape Mark 1. Almanacco Letterario Bompiani, Milão, 1962.

BARBOSA, Pedro. A Literatura Cibernética 1: Autopoemas Gerados por

Computador. Porto: Edições Árvore, 1977.

Árvore, 1980.

A Literatura Cibernética 2: Um Sintetizador de Narrativas. Porto: Edições Aforismos Gerados por Computador. Jornal de Notícias, Porto, p. 26, 5 de Junho de 1984.

. Máquinas Pensantes: Aforismos Gerados por Computador. Lisboa: Livros Horizonte, 1988. 
SINTEXT: Un Générateur de Textes Littéraires. In LENOBLE, Michel e Alain VUILLEMIN. Littérature et Informatique: La Littérature Générée par Ordinateur. Arras: Artois Presses Université, 1995, p. 189-202.

. A Ciberliteratura: Criação Literária e Computador. Lisboa: Edições Cosmos, 1996. 1996.

. Teoria do Homem Sentado: Livro Virtual. Porto: Edições Afrontamento,

A Renovação do Experimentalismo Literário na Literatura Gerada por Computador. Revista da UFP, Porto, v. 2, n. 1, p. 181-188, 1998.

. O Motor Textual: Livro Electrónico. Porto: Edições UFP, 2001.

. AlletSator-XPTO.Kosmos.2001. Porto: Edições Afrontamento, 2003.

Bubok, 2012.

. Ciberliteratura, Inteligência Computacional e Teoria Quântica. E-book.

. Correio eletrónico para Álvaro Seiça. Outubro de 2013.

CAMPOS, Haroldo de. I Punti Luminosi (entrevista a Ezra Pound). Correio Paulistano, São Paulo, 17 de Janeiro de 1960.

CRUZ, Marcos. Ernesto de Melo e Castro em Serralves. Diário de Notícias, Lisboa, 10 de Fevereiro de 2006.

$<$ http://www.dn.pt/especiais/interior.aspx?content_id=1012459\&especial=Serralve s\&seccao=ARTES\&page=-1> Acedido: 11/11/2013.

FINLAY, Ian Hamilton. Ian Hamilton Finlay: Selections. Ed. Alec Finlay. Berkeley: University of California Press, 2012.

FUNKHOUSER, Christopher T. A Vanguard Projected in Motion: Early Kinetic

Poetry in Portuguese. Sirena, Carlisle, v. 2005, n. 2, p. 152-164, 2005.

. Prehistoric Digital Poetry: An Archaeology of Forms, 1959-1995.

Tuscaloosa: University of Alabama Press, 2007.

HATHERLY, Ana. O Idêntico Inverso ou o Lirismo Ultra-Romântico e a Poesia Concreta. Diário de Notícias, Lisboa, 17 de Setembro de 1959.

. Anagramático. Lisboa: Moraes Editores, 1970.

. A Reinvenção da Leitura: Breve Ensaio Crítico Seguido de 19 Textos Visuais. Lisboa: Editorial Futura, 1975. 
A Experiência do Prodígio: Bases Teóricas e Antologia de Textos-Visuais Portugueses dos Séculos XVII e XVIII. Lisboa: INCM, 1983.

. Perspectivas para a Poesia Visual: Reinventar o Futuro. In AGUIAR, Fernando e Silvestre PESTANA (eds.) Poemografias: Perspectivas da Poesia Visual Portuguesa. Lisboa: Ulmeiro, 1985.

HATHERLY, Ana e E. M. de MELO E CASTRO (eds.) PO-EX: Textos Teóricos e Documentos da Poesia Experimental Portuguesa. Lisboa: Moraes Editores, 1981.

HELDER, Herberto. Fragmento de 'A Máquina de Emaranhar Paisagens'. In ARAGÃO, António e Herberto HELDER (org.) Poesia Experimental, Lisboa, Cadernos de Hoje, v. 1, p. 62-65, 1964.

. Electronicolírica. Lisboa: Guimarães Editores, 1964.

KAC, Eduardo (ed.) New Media Poetry: Poetic Innovation and New Technologies. Visible Language, Cincinnati, v. 30, n. 2, 1996.

Media Poetry: An International Anthology. Bristol: Intellect Books, 2007.

LATOUR, Bruno. Science in Action: How to Follow Scientists and Engineers through Society. Cambridge: Harvard University Press, 1987.

Reassembling the Social: An Introduction to Actor-Network-Theory. Oxford: Oxford University Press, 2005.

MELO E CASTRO, E. M. de. Ideogramas. Lisboa: Guimarães Editores, 1962. . Letter. The Times Literary Supplement, Londres, 25 de Maio de 1962. 1963, p. 38. Soneto Soma 14x. In Poligonia do Soneto. Lisboa: Guimarães Editores, . A Proposição 2.01: Poesia Experimental. Lisboa: Ulisseia, 1965. . Álea e Vazio. Lisboa: Moraes Editores, 1971. 1980. . As Vanguardas na Poesia Portuguesa do Século Vinte. Lisboa: ICALP, . Literatura Portuguesa de Invenção. São Paulo: Difel, 1983.

. Tudo Pode Ser Dito Num Poema. Uma Proposta para o Fim do Século XX. Colóquio/Letras, Lisboa, v. 89, p. 5-11, jan. 1986. 
. Infopoesia ou Poesia Informacional. Diário de Lisboa, Suplemento "Ler Escrever", Lisboa, p. 4, 29 de Outubro de 1987.

<http://hdl.handle.net/11002/fms_dc_351> Acedido: 20/11/2013.

. Poética dos Meios e Arte High Tech. Lisboa: Vega, 1988.

. O Fim Visual do Século XX e Outros Textos Críticos. São Paulo: Editora da Universidade de São Paulo, 1993.

. Sonhos de Geometria. VHS, 30'. Menú, Cuenca, v. 7/8, 1993.

. Considerações 'Apócrifas' sobre a Máquina de Trovar de

Meneses/Mairena/Machado. Colóquio/Letras, Lisboa, v. 132/133, p. 77-86, abr. 1994.

. Videopoetry. In KAC, Eduardo (ed.) New Media Poetry: Poetic Innovation and New Technologies. Visible Language, Cincinnati, v. 30, n. 2, p. 140-149, 1996. Reimp. in KAC, Eduardo (ed.) Media Poetry: An International Anthology. Bristol: Intellect Books, 2007.

. Finitos Mais Finitos: Ficção/Ficções. Lisboa: Hugin, 1996.

. Algorritmos: Infopoemas. São Paulo: Musa, 1998.

. O Caminho do Leve. Porto: Fundação de Serralves, 2006.

. Máquinas de Trovar: Poética e Tecnologia. Évora: Intensidez, 2008.

MOLES, Abraham. Art et Ordinateur. Tournai: Casterman, 1971.

NELSON, Theodor H. Literary Machines 93.1. Sausalito: Mindful Press, 1981.

PESTANA, Silvestre. Computer Poetry. ZX-81, ZX-82, Spectrum. 1981-83.

PORTELA, Manuel. DigLitWeb: Digital Literature Web. Online, 2005-2013. <http://www.ci.uc.pt/diglit/> Acedido: 17/01/2014.

. Flash Script Poex: A Recodificação Digital do Poema Experimental. Cibertextualidades, Porto, v. 3, p. 43-57, 2009.

. Google Earth: A Poem for Voice and Internet. Online, 2011.

<https://vimeo.com/56469197> Acedido: 17/01/2014.

. Autoautor, Autotexto, Autoleitor: O Poema como Base de Dados. Revista de Estudos Literários, Coimbra, v. 2, p. 203-240, 2012.

Scripting Reading Motions: The Codex and the Computer as SelfReflexive Machines. Cambridge: MIT Press, 2013. 
RASMUSSEN, Eric Dean e Scott RETTBERG. The ELMCIP Electronic Literature Knowledge Base: Project Report. Online, 2013. <http://elmcip.net/node/8836> Acedido: 21/11/2013.

REIS, Pedro. Portuguese Experimental Poetry: Revisited and Recreated. In CDROM da PO-EX. Vol. 2. CD-ROM. Porto: PO.EX, 2008. <http://poex.net/evaluation/PDF/reis_revisited.pdf> Acedido: 31/03/2014.

RIBEIRO, Eunice e Carlos Mendes de SOUSA. Antologia da Poesia Experimental Portuguesa: Anos 60 - Anos 80. Coimbra: Angelus Novus, 2004.

ROCHA, Luís. Silvestre Pestana: 45 Anos de Carreira Revisitados. Diário de Notícias Madeira, Funchal, p. 24, 5 de Fevereiro de 2013.

SÁ-CARNEIRO, Mário de. Manucure. In Poemas sem Suporte. PESSOA, Fernando e Mário de SÁ-CARNEIRO (dir.) Orpheu, Lisboa, v. 2, 1915.

SAMPAIO, Jaime Salazar. Poemas Propostos. Régua: Tip. Imp. do Douro, 1954.

SEIÇA, Álvaro. Transdução: Processos de Transferência na Literatura e Arte Digitais. Tese de Mestrado. Évora: Universidade de Évora, 2011.

. Anti-Spam: Reinventing Data. Parsons Journal for Information Mapping, Nova lorque, v. 4, n. 1, p. 1-14, 2012.

<http://pjim.newschool.edu/issues/2012/01/pdfs/ParsonsJournalForlnformationMa pping_Seica_Alvaro.pdf> Acedido: 25/10/2013.

The Transducer Function: An Introduction to a Theoretical Typology in Electronic Literature and Digital Art. CITARJournal, Porto, v. 4, n. 1, p. 71-79, 2012.

Electronic Literature and Online Literary Databases: The PO.EX and ELMCIP Cases. Riss, Trondheim, v. 14, n. 1, p. 89-102, 2014.

. E-CyberDigital Poetry. Online, 2014. <http://elmcip.net/node/9991>. Acedido: 04/02/2015.

SIER, André. CsO. Online, 2008. <https://vimeo.com/2716919> Acedido: 23/01/2014.

410. Online, 2010. <http://uunniivveerrssee.net/datascape/uunniipieces/410-2> Acedido: 23/01/2014.

SIMANOWSKI, Roberto. Digital Art and Meaning: Reading Kinetic Poetry, Text Machines, Mapping Art, and Interactive Installations. Minneapolis: University of Minnesota Press, 2011. 
TAVARES, Salette. Espelho Cego. Lisboa: Ática, 1957.

. "Al gar ismos Alfinete". ARAGÃO, António, Herberto HELDER e E. M. de MELO E CASTRO (org.) Poesia Experimental, Lisboa, Cadernos de Hoje, v. 2, s. p., 1966.

TORRES, Rui. Poesia em Meio Digital: Algumas Observações. In GAIO, Sofia e Luís Borges GOUVEIA (eds.) Sociedade da Informação: Balanço e Implicações. Porto: Edições UFP, 2004, p. 321-328.

Mar de Sophia. Online, 2005.

<http://telepoesis.net/mardesophia/index.html> Acedido: 25/10/2013.

. Amor de Clarice. Online, 2005. <http://telepoesis.net/amorclarice/> Acedido: 25/10/2013.

Poesia Encontrada. Online, 2007. <http://po-

ex.net/flash/foundpoetries2.swf> Acedido: 17/01/2014.

. Húmus Poema Contínuo. Online, 2008.

<http://telepoesis.net/humus/humus_index.html> Acedido: 22/11/2013.

. Poemas no Meio do Caminho. Online, 2008.

<http://telepoesis.net/caminho/> Acedido: 25/10/2013. 22/11/2013.

Poemário. Online, 2008. <http://telepoesis.net/poemario/>. Acedido:

(org.) CD-ROM da PO.EX: Poesia Experimental Portuguesa - Cadernos e Catálogos. Vols. 1 e 2. CD-ROM. Porto: PO.EX, 2008. <http://www.poex.net/evaluation/index.html> Acedido: 25/10/2013.

Poesia Experimental e Ciberliteratura: Por Uma Literatura Marginal izada. In CD-ROM da PO-EX. Vol. 1. CD-ROM. Porto: PO.EX, 2008. <http://www.poex.net/evaluation/PDF/torres_flup.pdf> Acedido: 25/10/2013.

. Um Corvo Nunca Mais. Online, 2009

<http://telepoesis.net/pessoa/menu.html> Acedido: 17/01/2014.

. 8 Brincadeiras para Salette Tavares. Online, 2010.

<http://telepoesis.net/brincadeiras/index.html> Acedido: 17/01/2014.

PoemAds: Sob o Signo da Devoração. Online, 2011.

<http://www.telepoesis.net/poemads/index.html> Acedido: 15/01/2014.

. 'The Dead Must Be Killed Once Again': Plagiotropia as Critical Literary Practice. ebr: Electronic Book Review. Online, August 5, 2012. 
<http://electronicbookreview.com/thread/electropoetics/plagio> Acedido:

$15 / 06 / 2014$.

TORRES, Rui e Luís Carlos PETRY (orgs.) Cibertextualidades 2: Ciberdrama e Hipermédia, Porto, 2007.

TORRES, Rui e Friedrich W. BLOCK. Poetic Transformations in(to) Digital. In CDROM da PO-EX. Vol. 2. CD-ROM. Porto: PO.EX, 2008. <http://www.poex.net/evaluation/PDF/torresblock_epoetry.pdf> Acedido: 25/10/2013.

TORRES, Rui e Sandy BALDWIN (eds.) PO.EX: Essays from Portugal on Cyberliterature and Intermedia. Morgantown: Center for Literary Computing/West Virginia University Press, 2014.

TRANQUADA, Luís. Silvestre Pestana - entrevista - Lonarte. Online, 6/12/2011. <http://youtu.be/fJj6ImQmxss> Acedido: 20/11/2013.

XISTO, Pedro. Carta de Pedro Xisto para E. M. de Melo e Castro [São Paulo, 4/11/62]. Zunái, Rio de Janeiro, v. 1, n. 1, online, ago. 2013. $<$ http://zunai.com.br/post/56772592455/carta-de-pedro-xisto-para-e-m-de-melo-ecastro> Acedido: 25/10/2013.

\section{Arquivos e Bases de Dados de Literatura Eletrónica}

ELMCIP: http://elmcip.net/

PO.EX: http://po-ex.net/

Electronic Literature Directory: http://directory.eliterature.org/

NT2: http://nt2.uqam.ca/

\section{Coleções e Antologias de Literatura Eletrónica}

Hayles, Katherine N., Nick Montfort, Scott Rettberg e Stephanie Strickland (eds.). Electronic Literature Collection, Volume 1. College Park, Maryland: ELO, 2006. http://collection.eliterature.org/1/

Castanyer, Laura Borràs, Talan Memmott, Rita Raley e Brian Kim Stefans (eds.). Electronic Literature Collection, Volume 2. Cambridge, Massachusetts: ELO, 2011. http://collection.eliterature.org/2/

Engberg, Maria, Talan Memmott e David Prater (eds.). Anthology of European Electronic Literature. Karlskrona: ELMCIP, 2012. http://anthology.elmcip.net/

\section{Centros de Investigação em Portugal}

CETIC: http://cetic.ufp.pt/ 
CECLICO: http://www.ufp.pt/investigacao/centros/ceclico

CLP: http://www.uc.pt/fluc/clp/

CECL: http://www.cecl.com.pt/

Texto recebido em: 05/02/2015.

Texto aceito em: 08/06/2015. 